\title{
New anticoagulants for the prevention of venous thromboembolism
}

This article was published in the following Dove Press journal:

Drug Design, Development and Therapy

2 April 2010

Number of times this article has been viewed

\section{Cecilia Becattini \\ Alessandra Lignani \\ Giancarlo Agnelli \\ Internal and Cardiovascular Medicine and Stroke Unit, University of Perugia, Italy}

Correspondence: Cecilia Becattini Internal and Cardiovascular Medicine and Stroke Unit, University of Perugia, Italy Tel +39075 5786424

Fax +39075 5782436

Email cecila.becattini@unipg.it

\begin{abstract}
Anticoagulant drugs have an essential role in the prevention and treatment of thromboembolic diseases. Currently available anticoagulants substantially reduce the incidence of thromboembolic events in a number of clinical conditions. However, these agents have limitations that strengthen the case for the development of new anticoagulants. An ideal anticoagulant should be at least as effective as those currently in use, as well as safe, simple to use, and widely applicable.

The majority of new anticoagulants currently under investigation are small molecules with a selective and direct anti-Xa or antithrombin action, allowing oral administration in fixed doses. These new agents are in different phases of clinical development. The anti-Xa agent rivaroxaban and the antithrombin agent dabigatran are already available for the prophylaxis of venous thromboembolism in some countries. Apixaban is in an advanced phase of clinical development and several anti-Xa agents are currently approaching phase III clinical trials. Promising results in terms of efficacy and safety profiles have been obtained with these agents in different clinical conditions. Differences in pharmacokinetics and pharmacodynamics could offer the potential for individualized anticoagulant therapies in the near future.
\end{abstract}

Keywords: anticoagulant therapy, antithrombotic therapy, anticoagulants, direct thrombin inhibitors, factor Xa inhibitors

\section{Introduction}

Antithrombotic prophylaxis is essential in order to reduce morbidity (symptomatic and asymptomatic venous thromboembolism) and mortality (overall mortality and fatal pulmonary embolism) in patients at risk for venous thromboembolism (VTE). ${ }^{1}$ The risk of bleeding complications is the trade-off for antithrombotic efficacy with all anticoagulant agents.

Heparin, either unfractionated (UFH) or low molecular weight (LMWH), fondaparinux and warfarin have been shown to be very effective for the prophylaxis of VTE. However, the parenteral route of administration can be a limitation to the use of heparin or fondaparinux, while the need for laboratory monitoring and ongoing dose adjustment is the main limitation to the use of warfarin.

Newer anticoagulant agents with the potential for oral administration in fixed doses without the need for regular laboratory monitoring and dose adjustments, or significant food and drug interactions, should improve the use of antithrombotic prophylaxis. Indeed, nearly half of the patients undergoing major surgery or hospitalized for medical illnesses do not receive appropriate antithrombotic prophylaxis. $^{2}$ 
Several new anticoagulant agents are currently in various phases of clinical development for the prophylaxis of VTE. This paper reviews the evidence for the efficacy and safety of the new anticoagulants for VTE prophylaxis in different clinical settings.

\section{Risk stratification}

Risk stratification is essential to identify candidates for antithrombotic prophylaxis (Table 1). VTE complications occur in $10 \%$ to $40 \%$ of patients admitted with a medical illness or undergoing general surgery, and in $40 \%$ to $60 \%$ of patients undergoing orthopedic surgery. ${ }^{1}$ The risk of VTE varies according to both patient-related and surgery-related risk factors. Patient-related risk factors include age, obesity, hormonal therapy, cancer, previous VTE, molecular thrombophilia, and chronic venous insufficiency. Surgery-related risk factors include type of surgery (eg, general, orthopedic, minor, major), length of surgery, and type of anesthesia. An individual's risk of VTE increases in the presence of multiple risk factors. The duration of postoperative immobilization and the occurrence of perioperative complications are additional risk factors for VTE in patients undergoing surgery. ${ }^{3}$

Major orthopedic surgery, eg, elective total knee replacement (TKR), hip replacement (THR) and hip fracture repair put patients at highest risk of VTE complications. Pulmonary embolism (PE) is the main cause of death in these patients, and is the most common cause of readmission to the hospital following THR. ${ }^{4}$ However, fatal PE is uncommon after major orthopedic surgery if antithrombotic prophylaxis is used. ${ }^{5,6}$ Minor arthroscopic procedures are associated with a lower risk of VTE than conventional orthopedic surgery. ${ }^{7}$

Patients hospitalized for a medical illness have an approximately eight-fold risk of VTE compared with the general population. ${ }^{8,9}$ VTE, proximal DVT, and fatal VTE occur in $10 \%$ to $20 \%, 4 \%$ to $5 \%$, and $1 \%$ of all patients hospitalized for medical illnesses, respectively. ${ }^{7,10-11}$ Previous VTE, stroke, heart failure, chronic obstructive.pulmonary disease, sepsis, and bed rest are risk factors for VTE in medical patients. ${ }^{10}$ The incidence of VTE in patients with cancer varies from $4 \%$ to $20 \%$, and is a leading cause of death in these patients. ${ }^{12,13}$ The risk of VTE in cancer patients is higher while in hospital for medical illnesses, during chemotherapy, and/or surgery. ${ }^{14-16}$

\section{New anticoagulants}

New anticoagulant agents under clinical development have been developed using advanced molecular technology that enables their effect to be targeted to a selected step or enzyme in the coagulation cascade. ${ }^{17-19}$ The large majority of new anticoagulants under clinical development are oral anti-Xa or anti-thrombin agents. Pharmacodynamic features of the newer anticoagulants are shown in Table 2.

Table I Risk stratification for the incidence of VTE

\begin{tabular}{|c|c|c|c|c|c|c|}
\hline Risk level & Distal DVT & Prox DVT & Fatal PE & DVT total & Patients & $\begin{array}{l}\text { Antithrombotic } \\
\text { prophylaxis }\end{array}$ \\
\hline \multirow[t]{2}{*}{ Low } & $<10 \%$ & $<1 \%$ & $<0.1 \%$ & $<10 \%$ & $\begin{array}{l}\text { Minor surgery in mobile } \\
\text { patients (eg, arthroscopic } \\
\text { surgery) }\end{array}$ & $\begin{array}{l}\text { Prophylaxis } \\
\text { recommended only for } \\
\text { patients with additional } \\
\text { risk factors }\end{array}$ \\
\hline & & & & $<10 \%$ & $\begin{array}{l}\text { Medical patients who are } \\
\text { fully mobile }\end{array}$ & $\begin{array}{l}\text { No prophylaxis } \\
\text { recommended }\end{array}$ \\
\hline \multirow[t]{2}{*}{ Moderate } & $10 \%-40 \%$ & $1 \%-10 \%$ & $0.1 \%-1 \%$ & $10 \%-40 \%$ & $\begin{array}{l}\text { General, gynecologic, } \\
\text { urologic surgery }\end{array}$ & $\begin{array}{l}\text { LMWH, UFH or } \\
\text { fondaparinux }\end{array}$ \\
\hline & & & & $10 \%-40 \%$ & $\begin{array}{l}\text { Medical patients, bed } \\
\text { rest, sick }\end{array}$ & $\begin{array}{l}\text { LMWH, UFH } \\
\text { or fondaparinux } \\
\text { recommended for acutely } \\
\text { ill hospitalized medical } \\
\text { patients with additional } \\
\text { risk factors* }\end{array}$ \\
\hline \multirow[t]{3}{*}{ High } & $40 \%-80 \%$ & $10 \%-30 \%$ & $>1 \%$ & $40 \%-80 \%$ & Hip or knee arthroplasty & $\begin{array}{l}\text { LMWH, fondaparinux or } \\
\text { adjusted-dose vitamin } \mathrm{K} \\
\text { antagonists }\end{array}$ \\
\hline & & & & $40 \%-80 \%$ & Hip fracture surgery & \\
\hline & & & & $40 \%-80 \%$ & $\begin{array}{l}\text { Major trauma, spinal } \\
\text { cord injury }\end{array}$ & LMWH or UFH \\
\hline
\end{tabular}




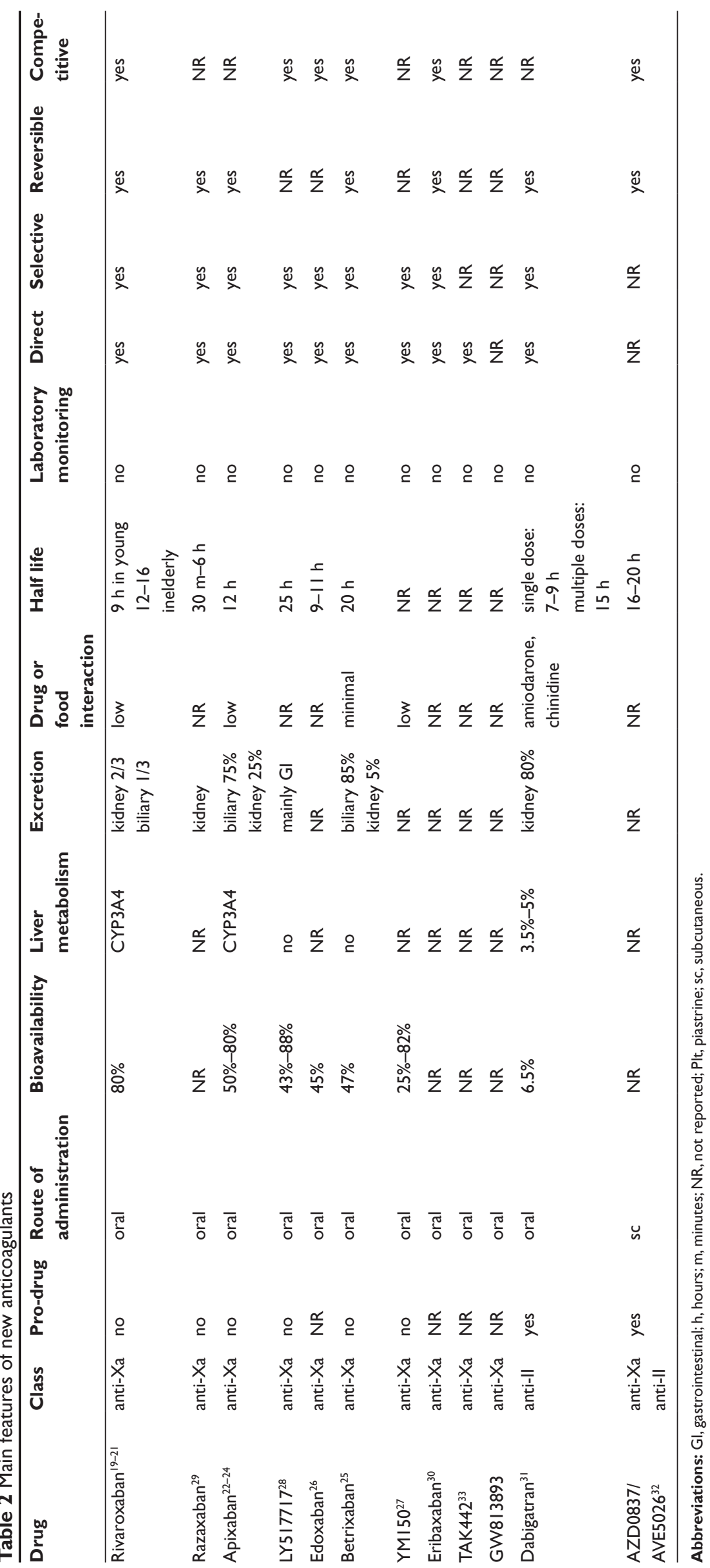




\section{Orthopedic surgery: Clinical trials with new anti-Xa agents}

A number of new anti-Xa and anti-thrombin agents are currently under evaluation for the prophylaxis of VTE in patients undergoing orthopedic surgery.

\section{Rivaroxaban}

Three Phase II, randomized, dose-ranging studies have been performed with rivaroxaban (initiated 6-8 hours post-surgery) in comparison with enoxaparin (using European or North American dosing regimens) in patients undergoing major orthopedic surgery (see Table 3). Two studies included patients undergoing THR and one study included patients undergoing TKR. ${ }^{34-36}$ The primary efficacy endpoint used in these studies was the composite of any DVT (proximal and/or distal), confirmed nonfatal PE, and all-cause mortality. In all studies treatment was continued until mandatory bilateral venography 5-9 days after surgery. Based on the results of these studies, the $10 \mathrm{mg}$ once daily regimen of rivaroxaban was selected for investigation in Phase III studies.

The Phase III development program for rivaroxaban comprised four Phase III clinical trials, known as the REgulation of Coagulation in major Orthopedic surgery reducing the Risk of DVT and PE (RECORD) studies, assessing the efficacy and safety of rivaroxaban $10 \mathrm{mg}$ once daily compared with enoxaparin given at US or European doses. The primary composite efficacy endpoint of the RECORD studies was any DVT, nonfatal PE, or death from any cause. The RECORD 1 and RECORD 3 studies showed that rivaroxaban started postoperatively was significantly more effective than enoxaparin started preoperatively in patients undergoing THR and TKR. ${ }^{37-38}$ The absolute risk reduction of the primary endpoint was $2.6 \%$ at 36 days in RECORD 1 and 9.2\% at two weeks in RECORD 3, with similar safety profiles. In RECORD 2, extended (five-week) prophylaxis with rivaroxaban was compared with shortterm (10-14 days) prophylaxis with enoxaparin in patients undergoing THR. ${ }^{39}$ As expected, the study showed that extended prophylaxis with rivaroxaban is superior to shortterm prophylaxis with enoxaparin in patients undergoing THR, without safety concerns. In RECORD 4, rivaroxaban was compared with enoxaparin, both started postoperatively and continued for 10-14 days in patients undergoing TKR ${ }^{40}$ Rivaroxaban was significantly more effective than enoxaparin (incidence of primary efficacy outcome at day 17 after surgery $6.9 \%$ and $10.1 \%$ in patients randomized to rivaroxaban or enoxaparin, respectively) in patients undergoing TKR. Major bleeding occurred in $0.7 \%$ patients randomized to rivaroxaban and in $0.3 \%$ patients randomized to enoxaparin.

A pooled analysis of the four RECORD studies has been performed to assess the clinical benefit of rivaroxaban compared with enoxaparin in terms of hard clinical endpoints. The analysis showed that rivaroxaban is more effective than enoxaparin for the prevention of symptomatic VTE and all-cause death in patients undergoing major orthopedic surgery, irrespective of age, weight, gender, or renal function. ${ }^{41}$ Rivaroxaban reduced the composite endpoint of symptomatic VTE, cardiovascular events, all-cause mortality, and major bleeding significantly more than enoxaparin $(P=0.004)$. A similar effect was observed in the incidence of symptomatic VTE and/or death at 10-14 days $(0.47 \%$ versus $0.97 \% ; P=0.001)$ and for the total study duration $(0.81 \%$ versus $1.63 \% ; P<0.001)$. However, rivaroxaban was associated with a higher incidence of major bleeding than enoxaparin at $10-14$ days $(0.34 \%$ versus $0.21 \%)$ and for the total study duration $(0.44 \%$ versus $0.27 \%){ }^{42}$ Further studies should address the issue of the cardiovascular rebound phenomenon to establish the safety of rivaroxaban.$^{43}$ Based on the results of the RECORD studies, rivaroxaban has been recently licensed for the prevention of VTE after elective hip and knee replacement in Europe and Canada. A Phase IV clinical trial is ongoing to assess additional information on the risk-benefit profile of rivaroxaban (NCT00831714 www.clinicaltrial.gov).

\section{Apixaban}

Apixaban was compared with enoxaparin (30 mg twice daily) and warfarin (INR 1.8-3.0) in a dose-finding study in 1238 patients undergoing TKR. ${ }^{44}$ All apixaban groups had lower primary efficacy event rates (composite of VTE [assessed by mandatory venography] and all-cause mortality during treatment) than either comparator. Based on these results, apixaban $2.5 \mathrm{mg}$ twice daily was selected for Phase III development.

Three Phase III trials have been designed to explore the efficacy and safety of apixaban for the prevention of thromboembolism after major orthopedic surgery (ADVANCE program). The primary efficacy outcome of these studies was the composite of DVT (by venography or diagnosed on symptoms), PE, and death from any cause during the treatment period. In the ADVANCE 1 trial apixaban did not meet the criteria for noninferiority compared with enoxaparin for prevention of VTE in patients undergoing TKR. ${ }^{45}$ The primary efficacy outcome occurred in $9 \%$ of patients in the apixaban group and in $8.8 \%$ in the enoxaparin group. 


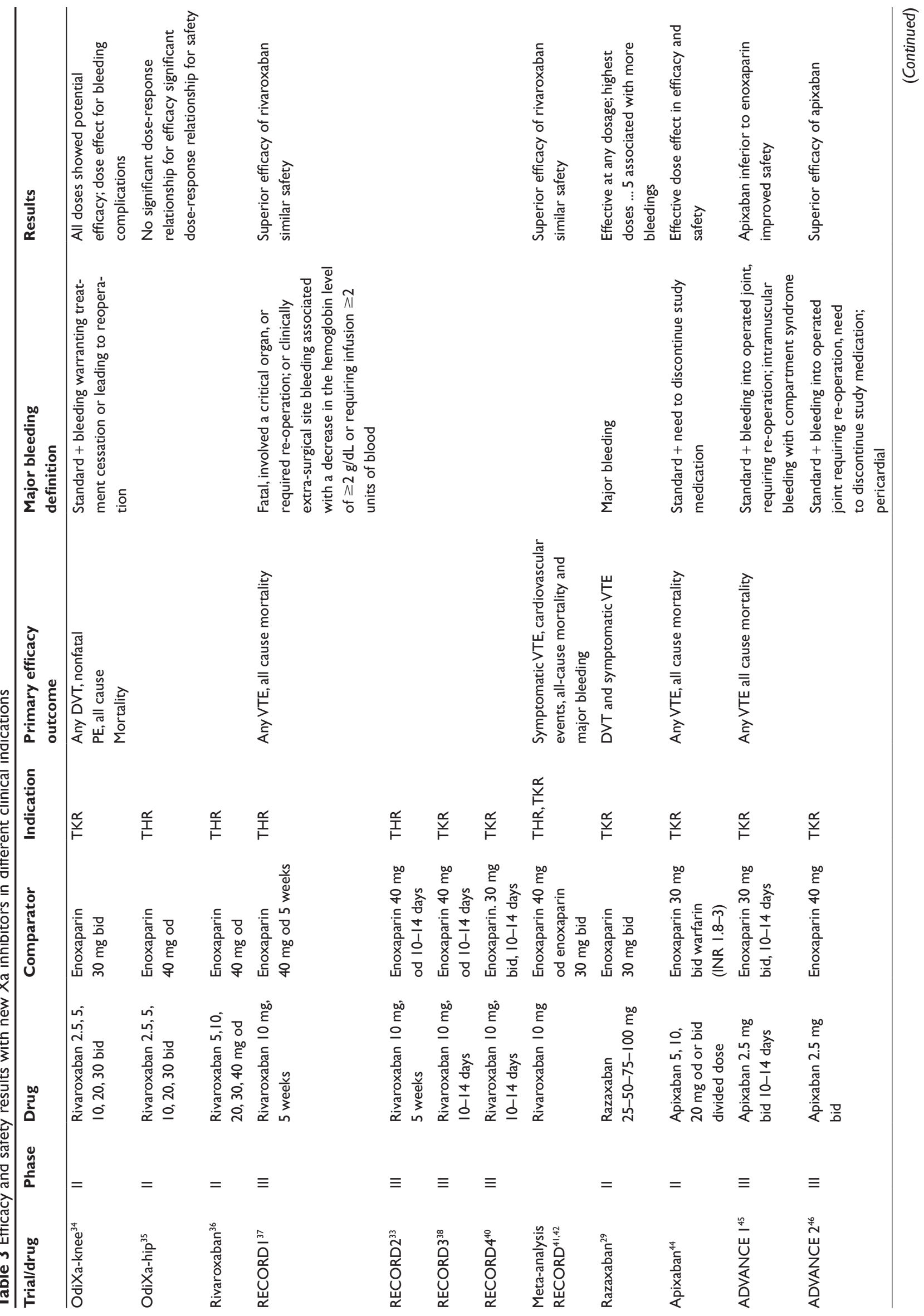




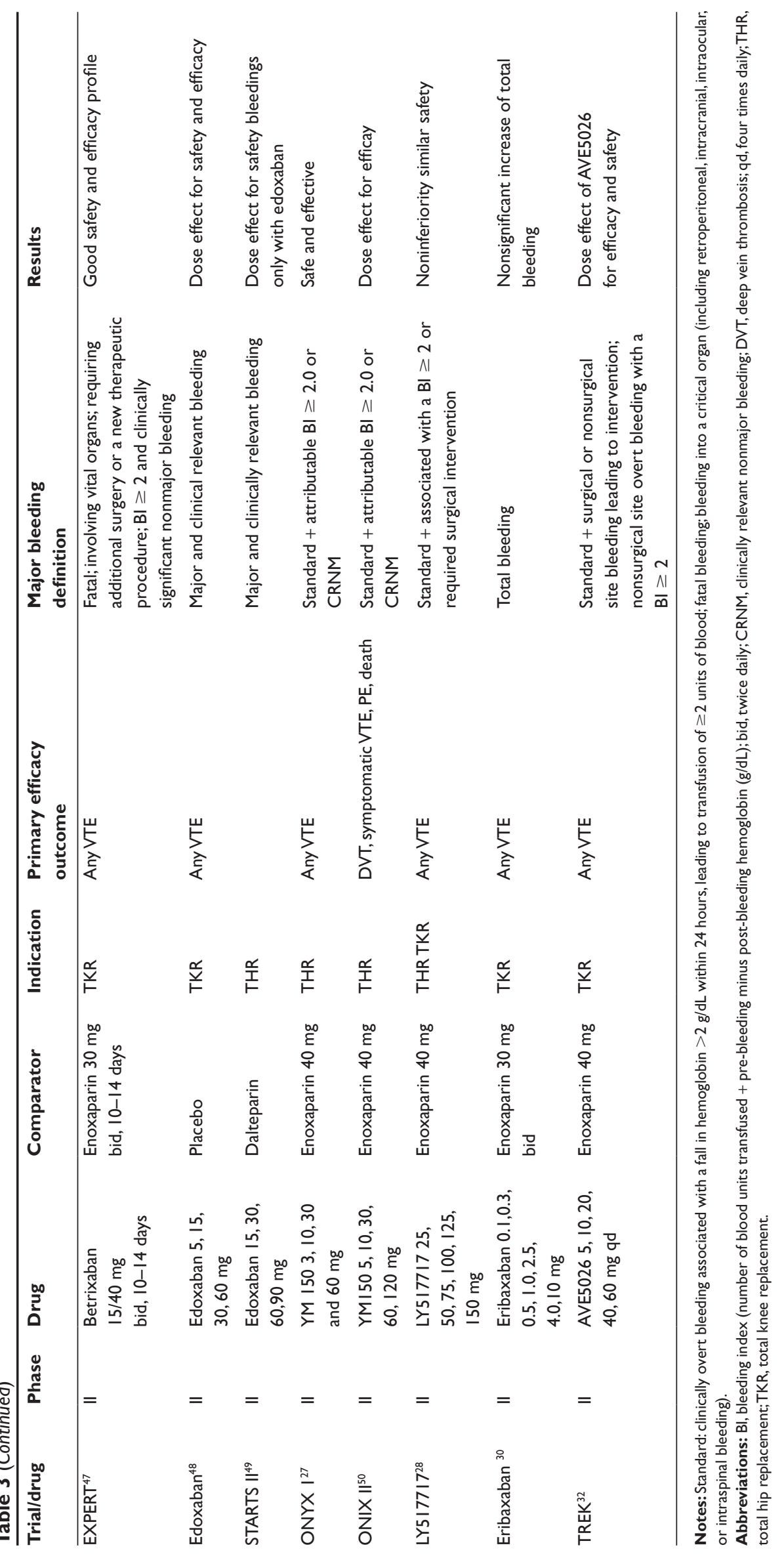


Major or clinically relevant nonmajor bleeding occurred in $2.9 \%$ of patients in the apixaban group and in $4.3 \%$ in the enoxaparin group $(P=0.03)$. Major bleeding occurred in $0.7 \%$ of patients in the apixaban group and in $1.4 \%$ in the enoxaparin group $(P=0.053)$.

In the ADVANCE 2 trial apixaban was compared with enoxaparin in patients undergoing TKR. ${ }^{46}$ The incidence of the primary efficacy outcome was $15.1 \%$ in the apixaban group and $24.4 \%$ in the enoxaparin group (relative risk 0.62 , 95\% CI 0.51-0.74). Proximal DVT, symptomatic nonfatal PE, and VTE-related death occurred in $1.1 \%$ of patients given apixaban and in $2.2 \%$ of patients given enoxaparin (relative risk $0.50,95 \%$ CI $0.26-0.97$ ). Clinically relevant bleeding (major or clinically relevant nonmajor) occurred in 3.5\% and $4.8 \%$ of the patients given apixaban and enoxaparin, respectively $(P=0.09)$. A Phase III randomized, double-blind study has been recently completed aimed at assessing the relative efficacy and safety of apixaban and enoxaparin for 35 days in patients undergoing elective THR surgery (www. clinicaltrial.gov NCT00423319).

\section{New anti-Xa in Phase II trials}

The oral anti-Xa betrixaban has been compared with enoxaparin, both started postoperatively in patients undergoing TKR.$^{47}$ DVT on mandatory unilateral venography or symptomatic proximal, or PE was reported through to day 14 in $20 \%, 15 \%$, and $10 \%$ of patients receiving increasing doses of betrixaban or enoxaparin, respectively. No bleeding complications were reported in the betrixaban $15 \mathrm{mg}$ group. Major bleeding occurred in $2.3 \%$ of patients in the enoxaparin group.

Two Phase II studies have explored the efficacy and safety of edoxaban for the prevention of VTE in major orthopedic surgery. Edoxaban reduced the incidence of VTE in a dosedependent fashion in comparison with placebo, without a significant increase in bleeding complications in patients undergoing TKR. ${ }^{48}$ Edoxaban was compared with dalteparin in patients undergoing THR. ${ }^{49}$ VTE occurred in $43.3 \%$ of patients in the dalteparin group and in $28.2 \%, 21.2 \%, 15.2 \%$, and $10.6 \%$ of patients receiving edoxaban, respectively. No bleeding was reported in the dalteparin group. The incidence of major or clinically significant nonmajor bleeding in the edoxaban groups ranged from $1.6 \%$ with lower doses to $2.3 \%$ for higher doses.

The efficacy and safety of YM150 for the prevention of VTE in patients undergoing THR was investigated in a Phase II study. ${ }^{27}$ Patients were randomized to once-daily YM150 starting 6-10 hours after hip replacement or to receive subcutaneous enoxaparin for 7-10 days. A significant dose-related trend in the incidence of VTE (confirmed symptomatic events and/or positive bilateral venography on the last treatment day) was observed with YM150. Three clinically relevant nonmajor bleedings were observed, one in the $3 \mathrm{mg}$ and two in the $10 \mathrm{mg}$ YM150 dose groups. The Phase II ONYX-2 study confirmed a significant decrease in the incidence of DVT, symptomatic VTE, PE, and death with increasing doses of YM150 in patients undergoing THR surgery. ${ }^{50}$ A number of Phase II and Phase III studies have been designed testing this agent, of which some are completed and some are currently ongoing. The aim of these studies is to evaluate the efficacy and safety of various doses of YM150 for the prevention of VTE in patients undergoing major orthopedic surgery in comparison with enoxaparin or warfarin (NCT00902928, NCT00913120, NCT00937911, NCT00408239, NCT00917254, NCT00595426 www.clinical trials.gov).

The oral anti-Xa razaxaban has been compared with twice daily $30 \mathrm{mg}$ enoxaparin in patients undergoing elective knee surgery. ${ }^{29}$ Razaxaban was effective at any evaluated dosage, but highest doses were associated with more bleedings than enoxaparin. No further study has been conducted with razaxaban.

In patients undergoing THR or TKR, prophylaxis with LY517717 resulted in a dose-dependent decrease in the incidence of VTE. The incidences of overall, symptomatic, or asymptomatic VTE was $19 \%, 19 \%$, and $16 \%$ with increasing doses of LY517717, respectively, compared with $21 \%$ for enoxaparin. All the doses of LY517717 met the predefined criteria for noninferiority compared with enoxaparin for the prevention of VTE after TKR or THR, with similar rates of bleeding complications. ${ }^{28}$ No studies are currently ongoing with this agent in patients undergoing orthopedic surgery.

In a dose-finding study, the efficacy of different doses of eribaxaban has been compared with that of enoxaparin in patients undergoing TKR. ${ }^{30}$ VTE occurred in 37\%, 37\%, $29 \%, 19 \%, 14 \%, 1.4 \%$, and $11 \%$ of patients receiving increasing doses of eribaxaban, respectively, compared with $18 \%$ of patients receiving enoxaparin. This study showed a nonsignificant dose-related increase in the incidence of total bleeding, mainly accounted for by minor bleeding.

A dose-finding study is currently underway to assess the efficacy and safety of TAK-442 in comparison with enoxaparin for the prevention of VTE after TKR (NCT00641732 www.clinicaltrial.gov). A Phase II study has also been designed to assess the efficacy and safety of GW813893 in 
the prophylaxis of VTE following TKR. (NCT00541320 www.clinicaltrial.gov).

In a Phase II study, 690 patients undergoing TKR surgery were randomized to AVE5026 or enoxaparin. ${ }^{32}$ A significant dose-response effect was observed with AVE5026, the incidence of total VTE ranging from $44.1 \%$ to $5.3 \%$. VTE occurred in $35.8 \%$ of patients receiving enoxaparin. The three highest doses of AVE5026 were significantly more effective than enoxaparin in reducing VTE. Also, a significant dose-response for AVE5026 was seen for major bleeding. The $20 \mathrm{mg}$ dose of AVE5026 was selected for future investigation in Phase III studies of the prevention of VTE in patients undergoing THR surgery and hip fracture surgery (NCT00697099, NCT00721760 www. clinicaltrial.gov). The results of a multicenter, randomized, double-blind study comparing the efficacy and safety of AVE5026 with that of enoxaparin for the prevention of VTE in patients undergoing elective knee replacement surgery will be available in the near future (NCT00718224 www. clinicaltrial.gov).

\section{Clinical trials with the new antithrombin agent dabigatran}

The clinical development program for dabigatran in orthopedic surgery is almost completed (Table 4). The Phase II program comprises the dose-finding BISTRO I and II studies. ${ }^{51,52}$ A significant dose-dependent decrease in VTE and an increase in major bleeding were observed with increasing doses of dabigatran in patients undergoing THR or TKR. The $150 \mathrm{mg}$ and $220 \mathrm{mg}$ once daily doses were selected for clinical development in the Phase III program.

In the RE-NOVATE study, dabigatran (starting 1-4 hours after surgery with half the dose) was compared with enoxaparin (starting the evening before surgery) both given for 28-35 days in 3494 patients undergoing THR. ${ }^{53}$ The composite of total VTE (symptomatic and asymptomatic) and death from all causes occurred in $6.7 \%$ patients in the enoxaparin group versus $6.0 \%$ and $8.6 \%$ of the patients in the dabigatran $220 \mathrm{mg}$ and $150 \mathrm{mg}$ groups, respectively. Both dabigatran doses met the criteria for noninferiority in comparison with enoxaparin, with no significant difference in major bleeding. In the RE-MODEL study 2076 patients undergoing TKR were randomized to receive dabigatran (starting 1-4 hours after surgery with half the dose) or subcutaneous enoxaparin. ${ }^{54}$ In this study, total VTE (symptomatic and asymptomatic) and death during treatment occurred in $37.7 \%$ of the patients in the enoxaparin group, compared with $36.4 \%$ and $40.5 \%$ of the patients in the dabigatran $220 \mathrm{mg}$ or $150 \mathrm{mg}$ groups, respectively. Both doses were found to be noninferior in comparison with enoxaparin. The incidence of major bleeding was similar across the three groups.

In the RE-MOBILIZE study, dabigatran (starting after surgery with half the dose) was compared with enoxaparin for 12 to 15 days after TKR. ${ }^{55}$ Total VTE and all-cause mortality occurred in $31 \%$ and $34 \%$ of the patients in the dabigatran $220 \mathrm{mg}$ and in the $150 \mathrm{mg}$ groups, respectively, compared with $25 \%$ of patients receiving enoxaparin. In this study dabigatran did not achieve the criteria for noninferiority. The safety profile was similar in all three groups $(0.6 \%$ in dabigatran groups and $1.4 \%$ in enoxaparin groups).

The results of the RE-MODEL, RE-NOVATE and RE-MOBILIZE studies were recently pooled in a metaanalysis that confirmed the noninferiority of dabigatran in comparison with enoxaparin $40 \mathrm{mg}$ once daily in patients undergoing major orthopedic surgery, with a similar safety profile. ${ }^{56}$ No significant differences in the incidence of liver enzyme elevation or coronary events between the treatment groups were observed in the Phase III development program. A trend toward increased gastrointestinal bleeding has been suggested with dabigatran in long-term indications.

The clinical development of dabigatran in orthopedic surgery is continuing with a Phase III study on the efficacy and safety of dabigatran (110 mg on the day of surgery followed by $220 \mathrm{mg}$ once daily), compared with enoxaparin $40 \mathrm{mg}$ for 28-35 days, in patients undergoing elective THR (NCT00657150 www.clinicaltrials.gov). In another study, patients undergoing TKR will receive in-hospital prophylaxis with nadroparin and dabigatran (110 mg twice daily) for 10 days after discharge from hospital (NCT00868179 www. clinicaltrials.gov).

Observational Phase IV studies of the safety and efficacy of dabigatran in predefined subpopulations of patients at increased risk of bleeding or VTE or with moderate renal impairment (creatinine clearance $30-50 \mathrm{~mL} / \mathrm{min}$ ) in a Mexican population are also about to start (NCT00847301, NCT00846807, NCT00967447 www.clinicaltrials.gov). Dabigatran has recently been licensed in Europe and in Canada for thromboprophylaxis in patients undergoing hip and knee replacement.

\section{Prevention of VTE in general surgical patients}

Two studies are currently ongoing aimed at assessing the efficacy and safety of new anticoagulant agents in the prevention of VTE in patients undergoing major abdominal 
Table 4 Efficacy and safety results with new II inhibitors in different clinical indications

\begin{tabular}{|c|c|c|c|c|c|c|c|}
\hline Trial/drug & Phase & Drug & Comparator & Indication & $\begin{array}{l}\text { Primary } \\
\text { efficacy } \\
\text { outcome }\end{array}$ & $\begin{array}{l}\text { Major bleeding } \\
\text { definition }\end{array}$ & Results \\
\hline BISTRO I5I & II & $\begin{array}{l}\text { Dabigatran } 12.5,25, \\
50,100,150,200, \\
300 \mathrm{mg} \text { bid or } 150, \\
300 \mathrm{mg} \text { od }\end{array}$ & No comparator & THR & Any DVT & Standard & $\begin{array}{l}\text { Effective with no } \\
\text { dose effect no } \\
\text { major bleedings }\end{array}$ \\
\hline BISTRO $\|^{52}$ & II & $\begin{array}{l}\text { Dabigatran 50, I50, } \\
225 \mathrm{mg} \text { bid or } \\
300 \mathrm{mg} \text { od }\end{array}$ & $\begin{array}{l}\text { Enoxaparin } \\
40 \mathrm{mg} \text { od }\end{array}$ & THR TKR & Any VTE & $\begin{array}{l}\text { Standard + surgical } \\
\text { or nonsurgical site } \\
\text { bleeding warranting } \\
\text { treatment cessation } \\
\text { or re-operation }\end{array}$ & $\begin{array}{l}\text { Dose-dependent } \\
\text { efficacy and } \\
\text { safety VTE lower } \\
\text { in I50, } 225 \mathrm{mg} \\
\text { bid and } 300 \mathrm{mg} \\
\text { od }\end{array}$ \\
\hline RE-MODEL ${ }^{54}$ & III & $\begin{array}{l}\text { Dabigatran } 150 \text { or } \\
220 \text { mg } 28-35 \text { days }\end{array}$ & $\begin{array}{l}\text { Enoxaparin } \\
40 \mathrm{mg} 6-10 \text { days }\end{array}$ & TKR & $\begin{array}{l}\text { Any VTE and } \\
\text { death from } \\
\text { all causes }\end{array}$ & & $\begin{array}{l}\text { Noninferiority } \\
\text { of dabigatran } \\
\text { similar safety }\end{array}$ \\
\hline RE-MOBILIZE ${ }^{55}$ & III & $\begin{array}{l}\text { Dabigatran } \\
150-220 \mathrm{mg} \\
28-35 \text { days }\end{array}$ & $\begin{array}{l}\text { Enoxaparin } \\
30 \mathrm{mg} \text { bid } 12-15 \text { days }\end{array}$ & TKR & & & $\begin{array}{l}\text { Inferiority of } \\
\text { dabigatran } \\
\text { similar safety }\end{array}$ \\
\hline RE-NOVATE ${ }^{53}$ & III & $\begin{array}{l}\text { Dabigatran } \\
150-220 \mathrm{mg} \\
28-35 \text { days }\end{array}$ & $\begin{array}{l}\text { Enoxaparin } \\
40 \mathrm{mg} 28-35 \text { days }\end{array}$ & THR & & & $\begin{array}{l}\text { Noninferiority } \\
\text { of dabigatran } \\
\text { similar safety }\end{array}$ \\
\hline $\begin{array}{l}\text { Dabigatran } \\
\text { metanalysis }^{56}\end{array}$ & & $\begin{array}{l}\text { Dabigatran } \\
220 \text { mg, I } 50 \text { mg }\end{array}$ & $\begin{array}{l}\text { Enoxaparin } 40 \mathrm{mg} \\
\text { Enoxaparin } 30 \mathrm{mg}\end{array}$ & TKR THR & $\begin{array}{l}\text { Any VTE and } \\
\text { death from } \\
\text { all causes }\end{array}$ & & $\begin{array}{l}\text { Noninferior } \\
\text { to enoxaparin } \\
40 \mathrm{mg} \text { Similar } \\
\text { safety }\end{array}$ \\
\hline
\end{tabular}

Notes: Standard: clinically overt bleeding associated with a fall in hemoglobin $>2 \mathrm{~g} / \mathrm{dL}$ within 24 hours, leading to transfusion of $\geq 2$ units of blood; fatal bleeding; bleeding into a critical organ (including retroperitoneal, intracranial, intraocular, or intraspinal bleeding).

Abbreviations: THR, total hip replacement; TKR, total knee replacement; VTE, venous thromboembolism.

surgery. One is a Phase III, randomized, double-blind study comparing the efficacy and safety of AVE5026 (given once daily by subcutaneous injection) with enoxaparin (40 mg once daily) (NCT00679588 www.clinicaltrials. gov, see Table 5).

The other is a Phase III open-label study aimed at evaluating the efficacy and safety of the oral anti-Xa YM150 for prevention of VTE and all-cause death in patients undergoing major abdominal surgery in comparison with mechanical prophylaxis (NCT00942435 www.clinicaltrials.gov).

\section{Prevention of VTE in medical patients}

Several studies are currently ongoing or are about to start with new anticoagulant agents for the prevention of VTE in patients hospitalized for acute medical illnesses.

A Phase III study has been recently completed and the results will be available in the near future for AVE5026 in comparison with enoxaparin for the prevention of VTE in patients hospitalized for acute medical illnesses (NCT00714597 www.clinicaltrial.gov).
A randomized, double-blind trial is currently ongoing aimed at comparing the efficacy and safety of rivaroxaban (10 mg once daily) given for 31-39 days with that of enoxaparin (40 mg once daily) given for 6-14 days (NCT00571649 www.clinicaltrial.gov). The incidence of any VTE is diagnosed by compression ultrasonography is evaluated at the end of the treatment period.

A Phase III double blind study is evaluating apixaban ( $2.5 \mathrm{mg}$ twice daily) given for 30 days plus subcutaneous placebo for 6-14 days, with respect to enoxaparin (40 mg once daily) given for 6-14 days plus oral placebo for 30 days, in patients hospitalized for medical illnesses (NCT00457002 www.clinicaltrial.gov).

\section{Cancer patients}

Several clinical trials have compared different agents for the prophylaxis of VTE in patients undergoing surgery for cancer or evaluated the need for extended out-of-hospital prophylaxis in these patients. ${ }^{57-60}$

A Phase II study is currently underway to assess whether apixaban (5 mg once daily for 12 weeks) administered to 
Table 5 Ongoing phase II and III studies

\begin{tabular}{|c|c|c|c|c|c|}
\hline Drug & Dose & Comparator & Duration of therapy & Phase & Indication \\
\hline Apixaban & $2.5 \mathrm{mg}$ bid & Enoxaparin $40 \mathrm{mg}$ & 35 days & III & THR \\
\hline YM I50 & NR & Enoxaparin & NR & II III & THR (ONIX3) \\
\hline YM I50 & NR & Enoxaparin & NR & II & TKR (PEARLI) \\
\hline YM I50 & NR & Enoxaparin & NR & II III & TKR \\
\hline YM I50 & NR & Warfarin & NR & II & TKR (PEARL) \\
\hline YM I50 & NR & NR & NR & II III & THR \\
\hline YM I50 & NR & NR & NR & III & Hip fracture, lower extremities surgery \\
\hline TAK442 & $\begin{array}{l}10-20-40-80 \mathrm{mg} \text { bid or } \\
40-80 \mathrm{mg} \text { od }\end{array}$ & Enoxaparin & NR & II & TKR \\
\hline GW8I3893 & NR & NR & NR & & TKR \\
\hline AVE5026 & $20 \mathrm{mg}$ & Enoxaparin & 7 to 10 days & III & TKR (SAVE KNEE) \\
\hline AVE5026 & NR & Enoxaparin & 7 to 10 days & III & THR (SAVE-HIP I) \\
\hline AVE5026 & NR & Enoxaparin $40 \mathrm{mg}$ & 7 to 10 days & III & Hip fracture surgery (SAVE-HIP 2) \\
\hline Dabigatran & $\begin{array}{l}110 \mathrm{mg} \text { followed by } \\
220 \mathrm{mg} \text { od }\end{array}$ & Enoxaparin $40 \mathrm{mg}$ & $28-35$ days & III & THR (RE-NOVATE II) \\
\hline AVE5026 & NR & Enoxaparin $40 \mathrm{mg}$ & NR & III & Major abdominal surgery \\
\hline YM I50 & NR & Mechanical prophylaxis & NR & III & Major abdominal surgery \\
\hline Apixaban & $5 \mathrm{mg}$ od & Placebo & 12 week & II & Metastatic cancer \\
\hline AVE5026 & NR & Placebo & NR & III & $\begin{array}{l}\text { Cancer and chemotherapy (SAVE } \\
\text { ONCO) }\end{array}$ \\
\hline Rivaroxaban & $10 \mathrm{mg}$ & Enoxaparin $40 \mathrm{mg}$ & $\begin{array}{l}31-39 \text { days enoxaparin } \\
6-14 \text { days }\end{array}$ & III & Medical ill patients (MAGELLAN) \\
\hline Apixaban & $2.5 \mathrm{mg}$ bid & Enoxaparin $40 \mathrm{mg}$ & $\begin{array}{l}\text { Apixaban } 30 \text { days vs } \\
\text { enoxaparin } 14 \text { days }\end{array}$ & II & Medical ill patients (ADOPT) \\
\hline AVE5026 & NR & Enoxaparin & NR & III & $\begin{array}{l}\text { Medical ill patients with restricted } \\
\text { mobility }\end{array}$ \\
\hline
\end{tabular}

Abbreviations: bid, twice daily; NR, not reported (the studies have been described according to data reported on the web, www.clinicaltrials.gov); od, once daily.

patients with advanced or metastatic cancer for the prevention of VTE will be well tolerated compared with placebo (NCT00320255 www.clinicaltrial.gov).

A Phase III study comparing the efficacy and safety of AVE5026 (once daily subcutaneous injections) with placebo for the prevention of VTE in high-risk cancer patients undergoing chemotherapy is currently ongoing (NCT00694382 www.clinicaltrial.gov).

\section{Conclusions}

Several new anticoagulant drugs are currently in clinical development for the prophylaxis of VTE. New agents have the potential to make anticoagulant treatment and prophylaxis easier as they are mostly available for oral administration in fixed doses, have short half-lives, and rapid onset of action. Given their different mechanisms of action and pharmacokinetic properties, the new anticoagulants also offer the potential for anticoagulation to be tailored for individual patients. Whether different mechanisms of action (eg, anti-Xa or anti-IIa effect) can influence the efficacy and safety profiles of new anticoagulants is currently only speculative.

The real advantage of new anticoagulants is expected for chronic indications more than for time-limited ones. It is conceivable that the use of new anticoagulants for the prophylaxis of VTE will increase after their approval for long-term indications.

If these new agents complete clinical development and become available for clinical use, clinicians will have the potential to choose the optimal anticoagulant regimen on an individual patient basis, taking into account not only safety, efficacy, and the clinical setting, but also patient characteristics, including age, renal failure, and liver disease.

\section{Disclosures}

The authors report no conflicts of interest in this work.

\section{References}

1. Geerts W, Bergquist D, Pineo F, et al. Prevention of venous thromboembolism. American College of Chest Physicians' evidence-based clinical practice guidelines (8th ed). Chest. 2008;133:381S-453S. 
2. Cohen AT, Tapson VF, Bergmann JF, et al. Venous thromboembolism risk and prophylaxis in the acute hospital care setting (ENDORSE study): A multinational cross-sectional study. Lancet. 2008;371:387-394.

3. Heit JA. Venous thromboembolism: Disease burden, outcomes and risk factors. J Thromb Haemost. 2005;3:1611-1617.

4. Seagroatt V, Tan HS, Goldcre M. Elective total hip replacement: Incidence, emergency readmission rate and postoperative mortality. BMJ. 1991;303:1431-1435.

5. Dahl OE, Caprini JA, Colwell CW, et al. Fatal vascular outcomes following major orthopedic surgery. Thromb Haemost. 2005;93: 860-866.

6. Pellegrini V, Donaldson C, Farber D, Lehman E, Evarts C. The John Charnley Award: Prevention of readmission for venous thromboembolism disease after total hip arthroplasty. Clin Orthop. 2005;441:56-62.

7. Dahl OE, Gudmundsen TE, Haukeland L. Late occurring clinical deep vein thrombosis in joint-operated patients. Acta Orthop Scand. 2000;71:47-50.

8. Heit JA, Silverstein MD, Mohr DN, et al. Risk factors for deep vein thrombosis and pulmonary embolism: A population based case-control study. Arch Intern Med. 2000;160:809-815.

9. Anderson FA, Wheeler HB, Goldberg RJ, et al. A population based perspective of the hospital incidence and case fatality rates of deep vein thrombosis and pulmonary embolism: The Worcester DVT study. Arch Intern Med. 1991;151:933-938.

10. Samama M, Cohen AT, Darmon JY, et al. A comparison of enoxaparin with placebo for the prevention of venous thromboembolism in acutely ill medical patients. N Engl J Med. 1999;341:793-800.

11. Weitz J, Hirsh J, Samama MM. New anticoagulant drugs. Chest. 2004;126:265S-286S.

12. Prandoni P, Falanga A, Piccioli A. Cancer and venous thromboembolism. Lancet Oncology. 2005;6:401-410.

13. Khorana A, Francis C, Culakova E. Thromboembolism is leading cause of death in cancer patients receiving outpatient chemotherapy. J Thromb Haemost. 2007;5:632-634.

14. Heit J, Silverstein M, Mohr D, Petterson T, O'Fallon W, Melton LJ. Risk factors for deep vein thrombosis and pulmonary embolism: A population based case-control study. Arch Intern Med. 2000;160:809-815.

15. Agnelli G, Gussoni G, Bianchini C, et al. Nadroparin for the prevention of thromboembolic events in ambulatory patients with metastatic or locally advanced solid cancer receiving chemotherapy: A randomised, placebocontrolled, double-blind study. Lancet Oncol. 2009;10:943-949.

16. Gallus AS. Prevention of postoperative deep leg vein thrombosis in patients with cancer. Thromb Haemost. 1997;78:126-132.

17. Furie B, Furie BC. Molecular and cellular biology of blood coagulation. N Engl J Med. 1992;326:800-806.

18. Mann K, Butenas S, Brummel K. The dynamics of thrombin formation. Arterioscler Thromb Vasc Biol. 2003;23:17-25.

19. Kubitza D, Becka M, Wensing G, Voith B, Zuehlsdorf M. Safety, pharmacodynamics and pharmacokinetics of BAY 59-7939, an oral, direct Factor Xa inhibitor after multiple dosing in healthy male subjects. Eur J Clin Pharmacol. 2005;61:873-880.

20. Kubitza D, Becka M, Roth A, Mueck W. Dose escalation study of the pharmacokinetics and pharmacodynamics of rivaroxaban in healthy elderly subjects. Curr Med Res Opin. 2008;24:2757-2765.

21. Weinz C, Schwartz T, Pleiss J, et al. Metabolism and distribution of BAY 59-7939 - an oral, direct factor Xa inhibitor - in rat, dog and human. Drug Metab Rev. 2004;36:196.

22. Spyropoulos AC. Brave new world: The current and future use of novel anticoagulants. Thrombosis Research. 2008;123:29S-35S.

23. Raghavan N, Frost CE, Yu Z, et al. Apixaban metabolism and pharmacokinetics after oral administration to humans. Drug Metabolism and Disposition Fast Forward. 2009;37:74-81.

24. Kan H, Bing H, Grace JE, et al. Preclinical pharmacokinetics and metabolism of apixaban, a potent and selective factor $\mathrm{Xa}$ inhibitor. Blood. 2006;108:273.

25. Turpie AGG. New oral anticoagulants in atrial fibrillation. Eur Heart J. 2008;29:155-165.
26. Zafar M, Vorcheimer D, Gaztanaga J, et al. Antithombotic effects of factor Xa inhibition with DU-176b: Phase I study of an oral direct factor Xa inhibitor using an ex-vivo flow chamber. Thromb Haemost. 2007;98:883-888.

27. Eriksson B, Turpie A, Lassen M. A dose escalation study of YM150, an oral direct factor $\mathrm{Xa}$ inhibitor, in the prevention of venous thromboembolism in elective primary hip replacement. J Thromb Haemost. 2007;5:1660-1665.

28. Agnelli G, Haas S, Ginsberg J, Krueger K, Dmitrienko A, Brandt J. A phase II study of the oral factor Xa inhibitor LY517717 for the prevention of venous thromboembolism after hip or knee replacement. J Thromb Haemost. 2007;5:746-753.

29. Lassen M, Davidson B, Gallus A, et al. A Phase II randomized double blind, five-arm, parallel group, dose response study of a new oral acting Factor Xa inhibitor, razaxaban, for the prevention of deep vein thrombosis in knee replacement surgery. Blood. 2003;102:15.

30. Cohen A, Armstrong D, Gazdzik T, et al. An adaptative-design doseranging study of PD 0348292, a new oral factor Xa inhibitor, for the prophylaxis after total knee replacement surgery. Blood. 2008;112: Abstr 980.

31. Stangier J, Rathgen K, Stahle H, Gansser D, Roth W. The pharmacokinetics, pharmacodynamics and tolerability of dabigatran etexilate, a new oral direct thrombin inhibitor, in healthy male subjects. Br J Clin Pharmacol. 2007;64:292-303.

32. Lassen M, Dahl O, Mismetti P, Destrée D, Turpie AG. AVE5026, a new hemisynthetic ultra-low-molecular-weight heparin for the prevention of venous thromboembolism in patients after total knee replacement surgeryTREK: A dose-ranging study. J Thromb Haemost. 2009;7:566-572.

33. Perzborn E. Factor Xa inhibitors. New anticoagulants for secondary haemostasis. Hamostaseologie. 2009;29:260-267.

34. Turpie A, Fisher W, Bauer K, et al. BAY 59-7939: An oral, direct factor $\mathrm{Xa}$ inhibitor for the prevention of venous thromboembolism in patients after total knee replacement. A phase II dose-ranging study. J Thromb Haemost. 2005;3:2479-2486.

35. Eriksson BI, Borris L, Dahl OE, et al. Oral, direct Factor Xa inhibition with BAY 59-7939 for the prevention of venous thromboembolism after total hip replacement. J Thromb Haemost. 2006;4:121-128.

36. Eriksson BI, Borris L, Dahl OE, et al. A once-daily oral, direct Factor Xa inhibitor, Rivaroxaban (BAY 59-7939), for thromboprophylaxis after total hip replacement. Circulation 2006;114:2374-2381.

37. Eriksson BI, Borris LC, Friedman RJ, et al. Rivaroxaban versus enoxaparin for thromboprophylaxis after hip arthroplasty. $N$ Engl J Med. 2008;358:2765-2775.

38. Lassen MR, Ageno W, Borris LC, et al. Rivaroxaban versus enoxaparin for thromboprophylaxis after total knee arthroplasty. $N$ Engl J Med. 2008;358:26.

39. Kakkar AK, Brenner B, Dahl OE, et al. Extended duration rivaroxaban versus short-term enoxaparin for the prevention of venous thromboembolism after total hip arthroplasty: A double-blind, randomised controlled trial. Lancet. 2008;372:35-39.

40. Turpie A, Lassen M, Davidson B, et al. Rivaroxaban versus enoxaparin for thromboprophylaxis after total knee arthroplasty (RECORD 4): A randomized trial. Lancet. 2009;373:1673-1680.

41. Bauer KA, Turpie AGG, Lassen MR, Kakkar AK, Eriksson BI, Gent M. Effect on age, weight, gender and renal function in a pooled analysis of four rivaroxaban studies. [abstract] J Thromb Haemost. 2009.

42. Turpie AGG, Lassen MR, Kakkar AK, Eriksson BI, Gent M. Pooled analysis of four rivaroxaban studies: effects on symptomatic events and bleeding. [abstract] Blood. 2008, San Francisco CA.

43. Van Thiel D, Kalodiki E, Wahi R, Litinas E, Haque W, Rao G. Interpretation of benefit-risk of enoxaparin as comparator in the RECORD program: Rivaroxaban oral tablets $(10 \mathrm{mg}$ ) for use in prophylaxis in deep vein thrombosis and pulmonary embolism in patients undergoing hip or knee replacement surgery. Clin Appl Thromb Haemost. 2009:15;389-394.

44. Lassen MR, Davidson BL, Gallus A, Pineo G, Ansell J, Deitchman D. The efficacy and safety of apixaban, an oral, direct factor Xa inhibitor, as thromboprophylaxis in patients following total knee replacement. J Thromb Haemost. 2007;5:2368-2375. 
45. Lassen MR, Raskob GE, Gallus A, Pineo G, Chen D, Portman RJ. Apixaban or enoxaparin for thromboprophylaxis after knee replacement. N Engl J Med. 2009;361:594-604.

46. Lassen M, Gallus A, Pineo G, Raskob G. The advance-2 study: A randomized double-blind trial comparing apixaban with enoxaparin for thromboprophylaxis after total knee replacement. [abstract] J Thromb Haemost. 2009.

47. Turpie A, Bauer K, Davidson B, et al. A randomized evaluation of betrixaban, an oral factor Xa inhibitor for prevention of thrombolic events after total knee replacement (EXPERT). Thromb Haemost. 2009;101:68-76.

48. Fuji T, Fujita S, Tachibana S, et al. Randomized, double-blind, multidose efficacy, safety and biomarker study of the oral factor Xa inhibitor DU-176b compared with placebo for prevention of venous thromboembolism in patients after total knee arthroplasty. Blood. 2008;112:34.

49. Raskob G, Cohen A, Eriksson B, et al. Randomized double-blind multidose trial of the oral factor Xa inhibitor DU-176b versus LMW heparin (dalteparin) for prevention of venous thromboembolism after total hip replacement. Eur Heart J. 2008;29:609.

50. Eriksson BI, Turpie AG, Lassen MR, et al. Prevention of venous thromboembolism with an oral Factor Xa inhibitor, YM150, after total hip arthroplasy. A dose-finding study (ONYX-2). J Thromb Haemost. 2010; Epub ahead of print. Blood. 2007;110:A309.

51. Eriksson BI, Dahl OE, Ahnfelt L, Kälebo P, et al. Dose escalating safety study of a new oral direct thrombin inhibitor, dabigatran etexilate, in patients undergoing total hip replacement: BISTRO I. Thromb Haemost. 2004;2:1573-1580.

52. Eriksson BI, Dahl OE, Büller HR, Hettiarachchi R, et al. A new oral direct thrombin inhibitor, dabigatran etexilate, compared with enoxaparin for prevention of thromboembolic events following total hip or knee replacement: The BISTRO II randomized trial. J Thromb Haemost. 2005;3:103-111.

53. Eriksson BI, Dahl OE, Rosencher N, et al. Dabigatran etexilate versus enoxaparin for prevention of venous thromboembolism after total hip replacement: A randomised, double-blind, non-inferiority trial. Lancet. 2007;370:949-956.
54. Eriksson BI, Dahl OE, Rosencher N, et al. Dabigatran etexilate versus enoxaparin for the prevention of venous thromboembolism after total knee replacement: The RE-MODEL randomized trial. $J$ Thromb Haemost. 2007;5:2178-2185.

55. The RE-MOBILIZE Writing Committee. Oral thrombin inhibitor dabigatran etexilate vs North American enoxaparin regime for prevention of venous thromboembolism after knee arthroplasty surgery. The Journal of Arthroplasty. 2009;24:1.

56. Wolowacz SE, Roskell NS, Plumb JM, Caprini JA, Eriksson BI. Efficacy and safety of dabigatran etexilate for the prevention of venous thromboembolism following total hip or knee arthroplasty. A metaanalysis. Thromb Haemost. 2009;101:77-85.

57. Agnelli G, Bergqvist D, Cohen A, Gallus AS, Gent M. A randomized double-blind study to compare the efficacy and safety of fondaparinux with dalteparin in the prevention of venous thromboembolism after high risk abdominal surgery: The PEGASUS study. Br J Surg. 2006;106:347-352.

58. Di Carlo V, Agnelli G, Prandoni P, et al. Dermatan sulphate for the prevention of postoperative venouse thromboembolism in patients with cancer. DOS (Dermatan sulphate in Oncologic Surgery) Study Group. Thromb Haemost. 1999;82:30-34.

59. ENOXACAN Study Group. Efficacy and safety of enoxaparin versus unfractionated heparin for prevention of deep vein thrombosis in elective cancer surgery: A double-blind randomized multicentre trial with venographic assessment. Br J Surg. 1997;84:1099-1103.

60. Bergqvist D, Agnelli G, Cohen AT, et al. For ENOXACAN II Investigators. Duration of prophylaxis against venous thromboembolism with enoxaparin after surgery for cancer. $N$ Engl J Med. 2002;346: 975-980.
Drug Design, Development and Therapy

\section{Publish your work in this journal}

Drug Design, Development and Therapy is an international, peerreviewed open-access journal that spans the spectrum of drug design and development through to clinical applications. Clinical outcomes, patient safety, and programs for the development and effective, safe, and sustained use of medicines are a feature of the journal, which

\section{Dovepress}

has also been accepted for indexing on PubMed Central. The manuscript management system is completely online and includes a very quick and fair peer-review system, which is all easy to use. Visit http://www.dovepress.com/testimonials.php to read real quotes from published authors

Submit your manuscript here: http://www.dovepress.com/drug-design-development-and-therapy-journal 